\title{
Detection of Greenhouse Gas and Aerosol Influences on Changes in Temperature Extremes
}

\author{
Hideo Shiogama ${ }^{1}$, Nikolaos Christidis ${ }^{2}$, John Caesar ${ }^{2}$, Tokuta Yokohata ${ }^{1}$ \\ Toru Nozawa ${ }^{1}$ and Seita Emori ${ }^{1,3,4}$ \\ ${ }^{1}$ National Institute for Environmental Studies, Tsukuba, Japan \\ ${ }^{2}$ Met Office, Hadley Centre for Climate Prediction and Research, Exeter, UK \\ ${ }^{3}$ Center for Climate System Research, the University of Tokyo, Kashiwa, Japan \\ ${ }^{4}$ Frontier Research Center for Global Change, Japan Agency for \\ Marine-Earth Science and Technology, Yokohama, Japan
}

\begin{abstract}
Detection/attribution analyses of temperature extremes were carried out by comparing a new gridded observational dataset of daily maximum/minimum temperatures (HadGHCND) and the simulation of MIROC3.2. It was shown that significant anthropogenic warming is detectable in the annual warmest night, and the coldest day and night from 1950 to 1999, while human influence was not detected in the warmest day. These findings are in agreement with a previous study that examined the simulation of HadCM3. Human influence is also identified in the decrease in the number of frost days, but not with the increase in the number of summer days. Furthermore, it was suggested that half of the warming trend due to rising greenhouse gas concentrations is canceled out by other factors, predominantly aerosol cooling. It is expected that a rapid decline of aerosol emissions coupled with rising greenhouse gas concentrations would induce larger changes in temperature extremes in the future.
\end{abstract}

\section{Introduction}

A number of detection/attribution studies, comparing the historical monthly mean near surface temperature record and 20th century climate simulations of coupled atmosphere-ocean general circulation models (CGCMs), have provided evidence that rising concentrations of well-mixed greenhouse gases (WMGHGs) are largely responsible for the observed near surface temperature warming, at least over the past three to five decades, at global and regional spatial scales (see the reviews by Intergovernmental Panel on Climate Change (IPCC) 2001, and International ad hoc Detection and Attribution Group 2005). It has also been demonstrated that cooling due to anthropogenic aerosol emissions has potentially contributed greatly to counteracting the warming due to WMGHGs (e.g., Tett et al. 2002). Knowledge about the causes of past climate change enables us to constrain the uncertainties of future climate projections made by CGCMs (Stott and Kettleborough 2002; Hegerl et al. 2006; Stott et al. 2006).

In addition to detection/attribution studies of mean temperature, it is important to study changes in temperature extremes, because these have large societal and health impacts (Easterling et al. 2000; McMichael et al. 2006). However, until recently, there has been no highquality gridded dataset of daily temperature observations that covered a long time scale and global spatial scale, making it difficult to compare model simulations

Corresponding author: Hideo Shiogama, National Institute for Environmental Studies, Tsukuba, Ibaraki 305-8506, Japan. E-mail: shiogama.hideo@nies.go.jp. @2006, British Crown Copyright. and observations. Recently, an effort was made to compile comprehensive global datasets that contain daily maximum/minimum temperatures, or extreme indices (Gleason et al. 2002; Klein Tank et al. 2002; Caesar et al. 2006; Frich et al. 2002; Alexander et al. 2006 (A06)), and impacts of human activity on some temperature extreme indices were reported (Kiktev et al. 2003). Christidis et al. (2005, hereafter C05) is the first study that applied a standard detection/attribution approach to compare 20th century climate simulations performed by HadCM3 (Gordon et al. 2000), and the new gridded observational dataset of daily maximum/minimum temperatures from Caesar et al. (2006). They investigated the annual warmest/coldest values of daily maximum/minimum temperatures, which had been employed to test the detectability of anthropogenic signals in a perfect model study (Hergel et al. 2004). They found that human influences are detectable in changes in the annual warmest minimum temperature, and the annual coldest maximum/minimum temperatures from 1950 to 1999. However, human influence is not detectable in changes in the warmest maximum temperature, which has the smallest signal-to-noise ratio among these four indices.

Uncertainty about climate sensitivity causes different responses to external forcing among various CGCMs (IPCC 2001), resulting in different estimates of contributors to past climate change (Shiogama et al. 2006), and uncertainty of future climate projections (Stott et al. 2006). Therefore, it is worth confirming the findings of C05 by carrying out the same detection/attribution analysis using a different CGCM, MIROC3.2 (K-1 model developers 2004). This is the first aim of the present study. The second aim is to extend the analysis of C05 to other important temperature extreme indices. Furthermore, we will estimate the relative importance of WMGHGs and other forcing factors (including aerosol forcing) to past changes in temperature extremes. This is expected to yield valuable information about the causes of past climate change and the uncertainty of future climate projection.

\section{Data and methodology}

We use HadGHCND, a newly gridded dataset of daily near surface maximum/minimum temperature observations (Caesar et al. 2006). This is the same dataset employed by C05. This dataset covers land areas mainly over the Northern Hemisphere and Australia on a $2.5^{\circ}$ lat. by $3.75^{\circ}$ lon. grid during the 1946 to 2000 period.

We compare the observations with three ensembles of 20th century climate simulations performed by MIROC3.2. The first ensemble (hereafter GHGS) was forced with changes in WMGHGs; the second (hereafter ANTH) with changes in WMGHGs and the other anthropogenic factors consisting mainly of sulfate and 
(a) Observation

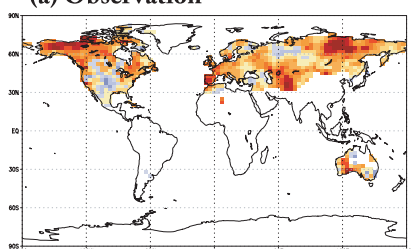

(c) ANTH

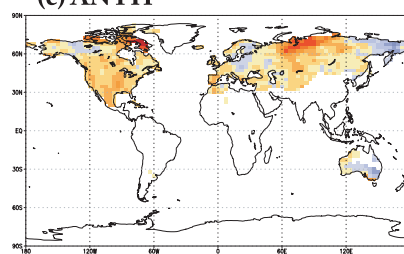

(b) GHGS

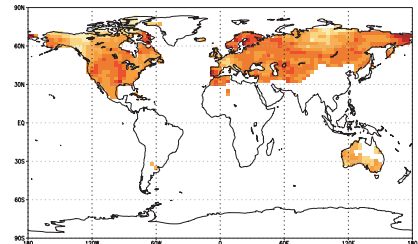

(d) FULL

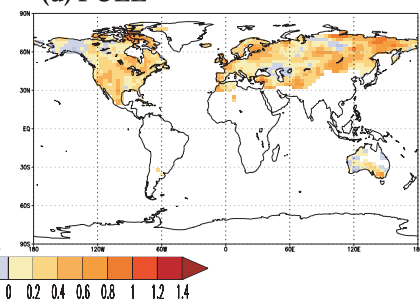

Fig. 1. Changes in the warmest night (1980-99 minus 1950-69; K) for (a) the observations, (b) GHGS, (c) ANTH, and (d) FULL.

carbonaceous aerosol emissions; and the third (hereafter FULL) with anthropogenic forcing and natural forcing, including solar irradiance and stratospheric volcanic aerosols. A detailed description of forcing is given by Nozawa et al. (2005). Each ensemble consists of four runs starting from different initial conditions taken from a 2270-yr stable pre-industrial control run, and the ensemble mean is analyzed. Model data is bi-linearly interpolated in latitude and longitude from its T42 grid to the grid of the observation data.

The present study investigates changes in the "annual most extreme value" indices examined by Hergel et al. (2004) and C05:

- warmest day (annual maximum of daily maximum temperature),

- warmest night (annual maximum of daily minimum temperature),

- coldest day (annual minimum of daily maximum temperature),

- coldest night (annual minimum of daily minimum temperature).

In addition, we analyze two "number of annual occurrence" indices (A06):

- summer days (annual number of days with daily maximum temperature $>25^{\circ} \mathrm{C}$ ),

- frost days (annual number of days with daily minimum temperature $<0^{\circ} \mathrm{C}$ ).

For both the observations and the model, these annual indices are computed when there are observations for more than 182 days per year at each grid. When annual indices exist for every year from 1950 to 1999, we compute five decadal averaged anomalies from the 1950 to 1999 mean.

Detection/attribution analysis is carried out by applying the optimal fingerprinting method (Allen and Tett 1999). This method computes a regression of the spatio-temporal pattern of the observed anomalies (y) onto (single or multi) model responses to external factors $\left(\mathrm{x}_{\mathrm{i}}\right)$ :

$$
\mathrm{y}=\sum\left(\mathrm{x}_{\mathrm{i}}-\mathrm{u}_{\mathrm{i}}\right) \beta_{\mathrm{i}}+\mathrm{u}_{0}
$$

A scaling factor, $\beta_{\mathrm{i}}$, is estimated by a total least squares (TLS) regression (Allen and Stott 2003), which takes into account the climate noise included in $\mathrm{x}_{\mathrm{i}}\left(\mathrm{u}_{\mathrm{i}}\right)$ as well as that in $\mathrm{y}\left(\mathrm{u}_{0}\right)$. If $\beta_{\mathrm{i}}$ is significantly larger than 0 , the simulated spatio-temporal change is detectable in the observations. Moreover, if $\beta_{\mathrm{i}}=1$, the simulated signal amplitude is consistent with the observations. If $\beta_{\mathrm{i}}$ is significantly smaller or larger than 1 , the simulated signal is overestimated or underestimated, respectively. To

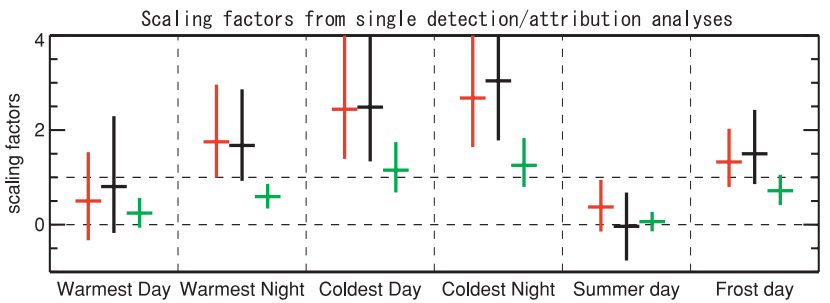

Fig. 2. Scaling factors and their 5-95\% uncertainty ranges from single detection/attribution analyses. Red, black, and green bars indicate scaling factors of FULL, ANTH, and GHGS, respectively.

optimize the signal-to-noise ratio, before the regression analysis, observed and model anomalies are spatially truncated onto T4 spherical harmonics and projected onto the leading 10 eigenvectors obtained from half of the 2270-yr control run. The results given below are insensitive to the exact number of eigenvectors used. The uncertainties on the scaling factor $\beta_{i}$ are estimated from the other half of the control run. For all indices, standard deviations of global mean decadal variations from the observations with linear trends removed fall within the minimum-maximum ranges from the control run. The residual test of Allen and Tett (1999) indicates that the residual in the regression is not inconsistent with control variability.

\section{Results}

Figure 1 shows the changes in the warmest night during the second half of the 20th century for the observations and the model. Warming is found over large parts of the globe in the observations and all the simulations. GHGS shows larger warming than the observations. Cooling due to anthropogenic aerosols cancels some degree of the GHGS warming, resulting in the smaller warming in ANTH than that found in GHGS. The difference between ANTH and FULL is not pronounced, suggesting that natural forcing factors have little impact on the warmest night during this period. Larger global warming is found in the coldest day/ night than the warmest night in both the observations and the model (not shown). The warmest day shows the smallest warming trend among these four indices (not
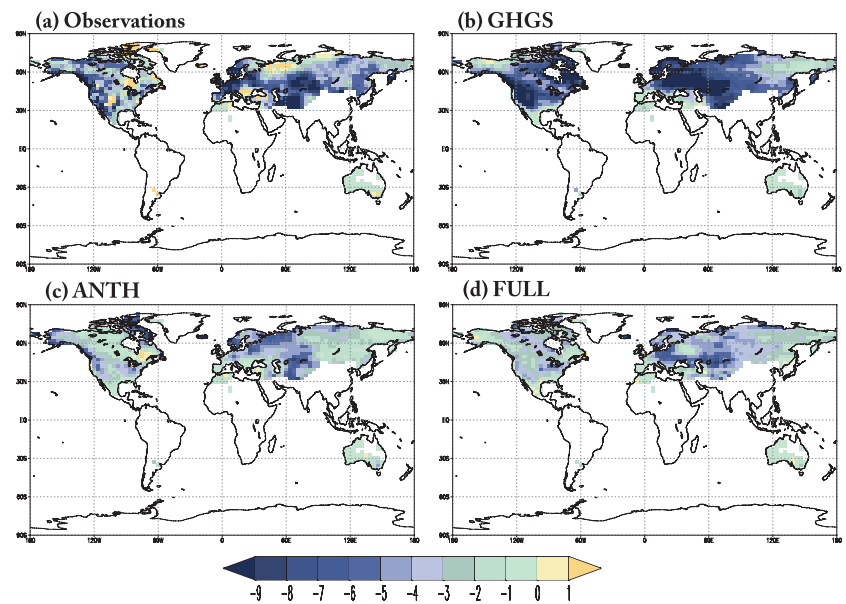

Fig. 3. Changes in the frost days (1980-99 minus 195069; days) for (a) the observations, (b) GHGS, (c) ANTH, and (d) FULL. 
shown).

The significance of the response to external forcing is tested by single detection/attribution analyses for FULL, ANTH, and GHGS (Fig. 2). For the warmest night and the coldest day/night, the scaling factors of GHGS are positive, suggesting that the influences of GHGS are detectable in the observed changes in these three indices. In the warmest night, the scaling factor of GHGS is smaller than 1, indicating that the response amplitude of GHGS is larger than the observations. The uncertainty range for the scaling factor of ANTH includes 1 , indicating that the response amplitude of ANTH is consistent with that of the observations. It is suggested that, together with the GHGS forcing, anthropogenic aerosol forcing is essential to reproduce the observed changes in the warmest night. Little difference is found between ANTH and FULL. It seems that natural forcings have no significant impact on the warmest night during this period. These findings about the warmest night are similar and generally in agreement with that of C05, confirming the robustness of the results of C05. However, ANTH of MIROC3.2 has the larger scaling factor than that of HadCM3, indicating that the ANTH response is smaller in MIROC3.2 than in HadCM3. Since their GHGS signals are similar, MIROC3.2 should have larger aerosol cooling than HadCM3. One of the factors that caused larger aerosol cooling of MIROC3.2 is carbonaceous aerosol forcing. Carbonaceous aerosol forcing acts as a cooling agent at the surface in MIROC3.2 (Nagashima et al. 2006), but is not considered in HadCM3.

For the coldest day/night, the scaling factors of GHGS are consistent with 1 like C05. The best estimates of the scaling factors for ANTH and FULL are larger than 1 like C05, i.e., both MIROC3.2 and HadCM3 tend to underestimate the changes in the coldest day/night. On the other hand, the ANTH and FULL scaling factors are larger in MIROC3.2 than that in HadCM3, indicating that MIROC3.2 has smaller ANTH and FULL responses. Human influence is not detectable in the warmest day as shown by $\mathrm{C} 05$.

Decreases in the number of frost days are found in the observations and the model (Fig. 3). The warming due to GHGS forcing results in large decreases in frost days. Cooling due to aerosol causes smaller signals of ANTH than those of GHGS. Natural forcing induces little difference between ANTH and FULL. Previous studies have also shown anthropogenic influences on the decrease in frost days (Frich et al. 2002; Kiktev et al. 2003; Meehl et al. 2004; A06; Tebaldi et al. 2006). Examining the experiments of 20th century climate and future projections from nine CGCMs (including MIROC3.2), Tebaldi et al. (2006) showed that the frost days decrease during 1960-2000 and the 21st century in all models. Therefore, there is a robust model consensus in the negative trends of the frost days. Increases in summer days are found in the observations and the simulations, but their amplitudes are smaller than the frost days (not shown). Single detection/attribution analyses show that the signal amplitude of FULL in the frost days is consistent with the observations, while anthropogenic influence is not detectable in the summer days (Fig. 2).

To evaluate the relative contributions from the GHGS forcing and the other factors (hereafter FULLGHGS), we apply a multi detection/attribution analysis for [GHGS, FULL-GHGS], which are obtained by a linear transformation of multi detection/attribution analysis for [GHGS, FULL] (Allen and Tett 1999). The radiative forcing shown by Takemura et al. (2006) indicates that the FULL-GHGS forcing should be dominated by aerosol forcing. Figure $4 \mathrm{a}$ shows scaling factors for GHGS and FULL-GHGS. For the warmest night and the frost days, both the signal amplitudes of GHGS and FULL-GHGS are consistent with the observations. On the other hand, for the coldest day/night,
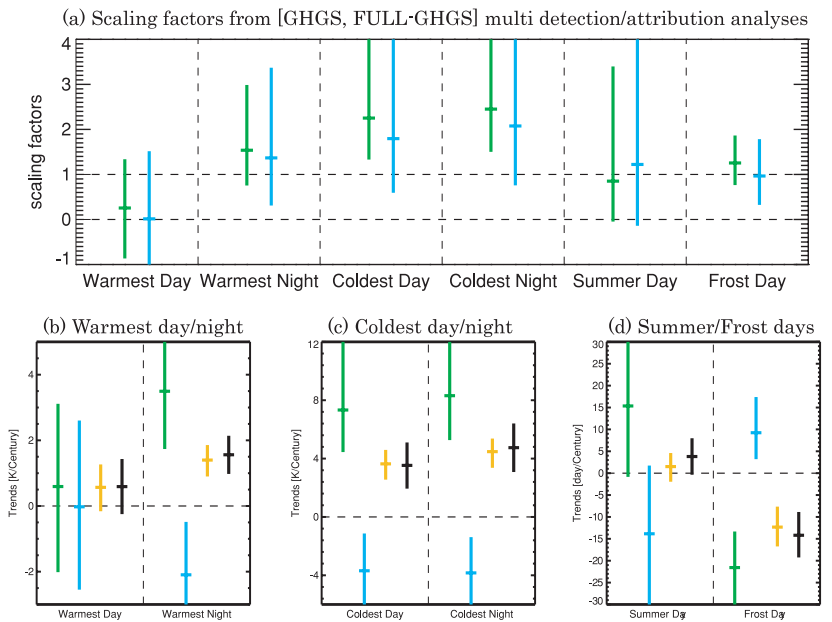

Fig. 4. (a) Scaling factors and their 5-95\% uncertainty ranges from [GHGS, FULL-GHGS] multi detection/ attribution analyses. Green and blue bars indicate scaling factors of GHGS, and FULL-GHGS, respectively. The lower 3 panels are global mean linear trends with 5-95\% uncertainty ranges for (b) warmest day/night, (c) coldest day/night, and (d) summer/frost days. Green and blue bars show GHGS and FULL-GHGS, which are inflated by their scaling factors, respectively. The yellow bar is the total reconstructed trend from the regression model. The observed trends are in black.

the GHGS responses are underestimated, while the signal amplitudes of FULL-GHGS are consistent with the observations. For the warmest day and the summer days, the GHGS and FULL-GHGS influences are not detectable.

Figures $4 \mathrm{~b}-\mathrm{d}$ depict global mean trends in the extreme indices attributable to the influences of GHGS and FULL-GHGS. Observed trends are well reproduced by the total trends from the regression model. For the warmest night and the coldest day/night, it is found that the FULL-GHGS cooling cancels about half of the GHGS warming. The increases in the number of frost days due to the FULL-GHGS cooling counteract the decreases due to the GHGS warming, reducing the amplitude of the changes in the frost days to half of the GHGS response. It is interesting that the relative importance of the GHGS and FULL-GHGS forcing in the frost days, which is a "number of annual occurrence" index, is almost same as that in the "annual most extreme value" indices. For the warmest day and the summer days, the best estimates of the observed trends are positive, but not significant, resulting in no detection of human influence. It has been suggested that the responses of mean temperature to the GHGS forcing are smaller in summer than in winter, weaker in day than in night (e.g., IPCC 2001). This is also true for the temperature extreme indices examined here. Further extending of data length toward the future would help detect anthropogenic influences from the daily maximum temperatures of the warm season. Otherwise, it is necessary to analyze another index with better signal-to-noise ratios.

\section{Summary}

The present study corroborates the findings of $\mathrm{C} 05$, which utilized HadCM3, regarding the changes in the annual warmest/coldest day/night from 1950 to 1999, by using another CGCM, MIROC3.2. It was confirmed that the influences of rising greenhouse gas concentrations are detectable in past changes in the warmest night, and the coldest day/night. Also, it was shown 
that MIROC3.2 has smaller responses to the anthropogenic forcing than HadCM3. To understand model sensitivities, and to achieve a more robust estimate of the reasons for past changes in extreme temperatures, we have started working on a multi-model analysis with these models. The results will be reported in another paper.

The observed decreases in frost days are attributable to decreases due to anthropogenic influences. On the other hand, it is difficult to detect human influences in the summer days and the warmest day, since these indices have poor signal-to-noise ratios.

Furthermore, we separated the contributions of greenhouse gas warming and the cooling due to other forcings to the changes in the temperature extremes with the exceptions of the warmest day and the summer days. The other forcings (aerosol cooling likely being the dominant component) mitigate the greenhouse gas influences by about half of the amplitude. Growing knowledge of the serious health effects of aerosol would lead to efforts to reduce aerosol emissions (Andreae et al. 2005). In the future, a rapid decline of aerosol emissions coupled with rising greenhouse gas concentrations is likely to result in larger changes in the temperature extremes in addition to the mean temperature (Andreae et al. 2005). Amplification of changes in the temperature extremes could induce more serious societal and health impacts than changes in the mean temperature alone.

\section{Acknowledgments}

The authors thank the K-1 project members, S. Crawford, two reviewers and the editor for their comments, and M. Allen for his optimal detection code. This work was supported by Research Revolution 2002 (RR2002) and Grant-in-Aid 18740301 for Scientific Research of the Ministry of Education, Culture, Sports, Science and Technology of Japan, and by the Global Environment Research Fund (B-12) of the Ministry of the Environment of Japan. NC and JC were funded by the UK Department for Environment, Food and Rural Affairs under contract PECD $7 / 12 / 37$. The Earth Simulator and a NEC SX-6 at NIES were employed to perform the CGCM simulations.

\section{References}

Alexander, L. V., and co-authors, 2006: Global observed changes in daily climate extremes of temperature and precipitation, J. Geophys. Res., 111, D05109, doi:10.1029/ 2005JD006290.

Allen, M. R., and P. A. Stott, 2003: Estimating signal amplitudes in optimal fingerprinting, part I: Theory, Clim. Dyn., 21, 477-491.

Allen, M. R., and S. F. B. Tett, 1999: Checking for model consistency in optimal fingerprinting, Clim. Dyn., 15, 419-434.

Andreae, M. O., C. D. Jones, and P. M. Cox, 2005: Strong presentday aerosol cooling implies a hot future, Nature, 435, 1187-1190, doi:10.1038/nature03671.

Caesar, J., L. Alexander, and R. Vose, 2006: Large-scale changes in observed daily maximum and minimum temperatures: Creation and analysis of a new gridded data set, $J$. Geophys. Res., 111, D05101, doi:10.1029/2005JD006280.

Christidis, N., P. A. Stott, S. Brown, G. C. Hegerl, and J. Caesar, 2005: Detection of changes in temperature extremes during the second half of the 20th century, Geophys. Res. Lett., 32, L20716, doi:10.1029/2005GL023885.

Easterling, D. R., G. A. Meehl, C. Parmesan, S. A. Changnon, T. R. Karl, and L. O. Mearns, 2000: Climate Extremes: Observations, Modeling, and Impacts, Science, 289, 2068-2074.

Frich, P., and co-authors, 2002: Observed coherent changes in climatic extremes during the second half of the twentieth century, Clim. Res., 19, 193-212.

Gordon, C., and co-authors, 2000: The simulation of SST, sea ice extents and ocean heat transports in a version of the Hadley Centre coupled model without flux adjustments, Clim. Dyn., 16, 147-168.

Gleason, B., P. Groisman, T. C. Peterson, R. Vose, and R. Ezell, 2000: A new global daily temperature and precipitation dataset, paper presented at 13th Symposium on Global Change and Climate Variations, Am. Meteorol. Soc., Orlando, Fla.

Hegerl, G. C., T. J. Crowley, W. T. Hyde, and D. J. Frame, 2006: Climate sensitivity constrained by temperature reconstructions over the past seven centuries, Nature, 440, 1029-1032, doi:10.1038/nature04679.

Hegerl, G. C., F. W. Zwiers, P. A. Stott, and V. V. Kharin, 2004: Detectability of anthropogenic changes in annual temperature and precipitation extremes, J. Clim., 17, 36833700 .

Intergovernmental Panel on Climate Change, Climate Change, 2001: The Scientific Basis, Contribution of Working Group I to the Third Assessment Report of the Intergovernmental Panel of Climate Change, edited by J. T. Houghton et al., Cambridge Univ. Press, New York.

International ad hoc Detection and Attribution Group, 2005: Detecting and attributing external influences on the climate system: A review of recent advances, J. Clim., 18, 1291-1314.

K-1 Model Developers, 2004: K-1 coupled GCM (MIROC) description, K-1 Tech. Rep. 1, edited by H. Hasumi and S. Emori, 34 pp., Cent. For Clim. Syst. Res., Univ. of Tokyo, Tokyo.

Kiktev, D., D. M. H. Sexton, L. Alexander, and C. K. Folland, 2003: Comparison of modelled and observed trends in indices of daily climate extremes, J. Clim., 16, 3560-3571.

Klein Tank, A. M. G., and co-authors, 2002: Daily surface air temperature and precipitation dataset 1901-1999 for European Climate Assessment (ECA), Int. J. Climatol., 22, $1441-1453$.

McMichael, A. J., R. E. Woodruff, and S. Hales, 2006: Climate change and human health: present and future risks, Lancet, 367, 859-869.

Meehl, G. A., C. Tebaldi, and D. Nychka, 2004: Changes in frost days in simulations of twentyfirst century climate, Clim. Dyn., 23, 495-511, DOI 10.1007/s00382-004-0442-9.

Nagashima, T., H. Shiogama, T. Yokohata, T. Takemura, S. A. Crooks, and T. Nozawa, 2006: Effect of carbonaceous aerosols on surface temperature in the mid twentieth century, Geophys. Res. Lett., 33, L04702, doi:10.1029/ 2005GL024887.

Nozawa, T., T. Nagashima, H. Shiogama, and S. A. Crooks, 2005: Detecting natural influence on surface air temperature change in the early twentieth century, Geophys. Res. Lett., 32, L20719, doi:10.1029/2005GL023540.

Shiogama, H., T. Nagashima, T. Yokohata, S. A. Crooks, and T. Nozawa, 2006: Influence of volcanic activity and changes in solar irradiance on surface air temperatures in the early twentieth century, Geophys. Res. Lett., 33, L09702, doi: 10.1029/2005GL025622.

Stott, P. A., and J. A. Kettleborough, 2002: Origins and estimates of uncertainty in predictions of twenty first century temperature rise, Nature, 416, 723-726.

Stott, P. A., J. F. B. Mitchell, M. R. Allen, T. L. Delworth, J. M. Gregory, G. A. Meehl, and B. D. Santer, 2006: Observational constraints on past attributable warming and predictions of future global warming, J. Clim., 19, 30553069.

Takemura, T., Y. Tsushima, T. Yokohata, T. Nozawa, T. Nagashima, and T. Nakajima, 2006: Time evolutions of various radiative forcings for the past 150 years estimated by a general circulation model, Geophys. Res. Lett., 33, L19705, doi:10.1029/2006GL026666.

Tebaldi, C., K. Hayhoe, J. M. Arblaster, and G. A. Meehl, 2006: Going to the extremes: An intercomparison of modelsimulated historical and future changes in extreme events. Climatic Change, in press.

Tett, S. F. B., and co-authors, 2002: Estimation of natural and anthropogenic contributions to twentieth century temperature change, J. Geophys. Res., 107(D16), 4306, doi:10.1029/2000JD000028.

Manuscript received 12 June 2006, accepted 22 September 2006 SOLA: http://www.jstage.jst.go.jp/browse/sola/ 